\title{
L. On the gas voltaic battery.-Experiments made with a view of ascertaining the rationale of its action and its application to eudiometry
}

\author{
W.R. Grove Esq. M.A. F.R.S.
}

To cite this article: W.R. Grove Esq. M.A. F.R.S. (1844) L. On the gas voltaic battery.-Experiments made with a view of ascertaining the rationale of its action and its application to eudiometry, Philosophical Magazine Series 3, 24:160, 346-354, DOI: $10.1080 / 14786444408644871$

To link to this article: http://dx.doi.org/10.1080/14786444408644871

曲 Published online: 30 Apr 2009.

Submit your article to this journal ¿

Ш Article views: 4

View related articles $\sqsubset$ 
Hill near Callington, displays nothing but neutral beds, or interchanges, or interlockings, of killas and carbonaceous rocks, or of carbonaceous rocks fracturing and piercing through the killas prior to the latter overwhelming them by its enormous accumulations.

The Boscastle sections however, on the other hand, are so readily comprehensible and simple as scarcely to admit a doubt of it, corroborated as they are by the coast cliffs to Tintagel, where the anthracitic schists, which are seen in mass at Boscastle supporting the killas in almost a tabular form, are observed to be continued upwards among the pale green roofing-slates by repeated interpolations, of which ready examples may be seen close by the church at Trevalga, and a little further south at Treworthat.

Such are the natural subdivisions of the great killas group, founded on peculiarly appropriate types and continuity of series, guided by which I trust I have sufficiently shown that I have relied on, or been misled by, nothing which was arbitrary or inconstant.

Its position as the crowning extremity of a magnificent, consecutive, and abundantly-varied series (as yet unrivalled by any hitherto developed by rigid and direct analysis), I have endeavoured to show as clearly and in as much detail as the nature of the communication admits, and so far its place in the European system may be determined and mapped down with certainty, if it shall eventually be shown, as I confidently anticipate it will be, that $I$ have been correct in my views, that the entire Devonian and Cornish group is based on (probably the upper beds of) the old red sandstone.

L. On the Gas Voltaic Battery.-Experiments made with a viere of ascertaining the rationale of its action and its application to Eudiometry. $B y$ W. R. Grove, Esq., M.A., F.R.S., Professor of Experimental Philosopiny in the London Institution.

(Continued from p. 278.)

F XPERIMENT 7, - I charged two batteries of two cells each, with hydrogen and dilute sulphuric acid in the alternate cells. When tested by jodide of potassium, each battery gave notable effects. One of these batteries was then placed, together with a cup containing phosphorus, in a shallow vessel of water; the phosphorus was ignited and a large glass vessel inverted over the whole; the terminal wires of the battery, carefully protected by thick coatings of cement, passed under the edge of this vessel through the water, the 
exterior surface of which was covered with oil, more effectually to prevent the absorption of air. The terminal wires were then united and left so. After two hours, when the oxygen of the surrounding atmosphere had been exhausted by the phosphorus, the effect became more feeble, but continued throughout the evening. The next morning, however, the inclosed battery produced not the slightest effect upon the iodide, the liquid had risen in the hydrogen tubes about 0.2 cubic inch, but no other effect was perceptible. On the other hand, in the battery which had been placed by its side, charged in the same way, and similar in every respect but in the fact of being exposed to the atmospheric air, a very decided effect was produced; hydrogen had been evolved from one of the platinums to the extent of 0.3 cubic inch in the cell containing liquid, and a decided effect was produced on the iodide. The two batteries were left in this state for three more days; the decomposition and the evolution of hydrogen continued in the exposed battery, but none was perceptible in the inclosed one, although the liquid had risen a little more, viz. $0 \cdot 1$ cubic inch in the hydrogen tubes of the latter. After the four days above mentioned, the jar of nitrogen which covered the battery was taken away, and the action of the battery was tested by iodide of potassium. At first there was no action, but after about fifteen minutes, a slight action was perceptible; this gradually increased, and in two hours the action was equal to that of the battery which had been from the first exposed to the atmosphere. I cannot but regard this experiment as a conclusive negation of that view which regards hydrogen and water as the efficient agents in the gas battery. The opinion appears to me to have arisen from the circumstance of our working always in an atmosphere containing oxygren, and also from the fact of this latter gas being more soluble than hydrogen *. If we lived in an atmosphere of hydrogen, and if this gas were equally or more soluble than oxygen, I have little doubt that the converse effects would be observed. A battery charged with hydrogen in one set of tubes and acidulated water in the alternate ones, at first gives an effect nearly equal to an oxyhydrogen gas battery, but the action rapidly declines in the former, while it is constant in the latter. Even the ordinary action of the gas battery when charged with oxygen and hydrogen appears to me unanswerable as to the point I am now discussing. When we see a battery of a number of cells at work, and the liquid gradually rising in the oxygen

* The tendency of oxygen to combine with platinum may also have its influence. See M. De La Rive's various experiments on this subject, Bibl. Univ passim. 
tubes, just in the proportion in which oxygen gas is eliminated in the voltameter, and when in a similar battery placed by its side, similarly charged, but not connected in closed circuit, not the slightest rise takes place in any tube, it seems impossible to adopt the conclusion that the oxygen has nothing to do with the current. Here we have no slight galvanoscopic effects, but chemical effects capable of quantitative admeasurement, capable of being continued to an extent only limited by the size of the apparatus, and equivalent to the chemical effects observable at the voltameter. If, on the other hand, hydrogen and water be the only active elements, what becomes of the hydrogen? If it combine with the water, we undoubtedly should by this means be able to obtain a suboxide of hydrogen*, a result of which I have not seen the slightest symptom in a long course of experiments on this subject. Even if we assume the action of the oxygen to be a depolarizing one, as suggested by $\mathrm{Dr}$. Schœnbein, this comes to the same thing, as this depolarization can only be accounted for as being effected by the combination of the oxygen with hydrogen; and we might conversely assume this combination to be the efficient cause of the current, and the depolarization to take place in the hydrogen tubes. It seems to me that the effects at both anode and cathode are reciprocally dependent. The matter appears to me so clear that I should not have entered into detail upon it, were it not for the published letter of Dr. Schœnbein above mentioned, and that the superiority of the hydrogen is prima facie very striking; knowing also the fondness with which we all adhere to preconceived opinions, as the consideration of the action of spongy or clean platinum on mixed gases led me to the discovery of the gas battery, I felt that I might be too apt to measure the correctness of my opinions by the success of the experiments to which they led, and therefore hesitated too confidently to rest upon what appeared to my mind positive demonstration.

Having verified the rationale of the action of the gas battery, I now sought to extend it to other gases, and caused arrangements of ten cells to be charged with such gases as were sufficiently insoluble to remain in the tubes time enough for experimental investigation. In all the following experiments, besides the ten cells charged in series, a single cell charged with similar gases and electrolyte was placed by the side, but with the terminals unconnected: thus, when the battery circuit had been closed for some time, by comparing the changes which had taken place in the battery tubes with those in the

* I see by a recent paper of Dr. Schœnbein that he believes this to be the case, Archives de l'Electricite, No. 7, p. 73. 
detached and unconnected pair, the effects due to solution, local currents, or other causes could be abstracted from those due to circulating voltaic action.

I shall arrange the following experiments in the order in which $I$ instituted them, making such comments as may be necessary to explain my own deductions from the resulting phænomena. When not otherwise mentioned, the electrolyte will be considered as dilute sulphuric acid, sp. gr. $1 \cdot 2$.

Experiment 8.-A battery charged with oxygen and protoxide of nitrogen produced no effect upon iodide of potassium. Examined next day the liquid had not risen in the oxygen tubes; in the protoxide tubes it had risen to an average of 0.3 cubic inch, both in the battery and detached pair.

Experiment 9.-Oxygen and deutoxide of nitrogen produced a slight effect upon the iodide; the effect subsided after the circuit had been complete for a few minutes. On examining the battery after the circuit had been closed for twentyfour hours, the liquid in the oxygen tubes had not risen; in the tubes containing deutoxide of nitrogen, the liquid had risen somewhat unequally in the different tubes to an amount averaging 0.2 cubic inch; in the detached pair it had risen to the same amount; not the slightest voltaic effect was now produced by the terminal wires.

Experiment 10.-Oxygen and olefiant gas decomposed the iodide, but rather feebly; after the circuit had been closed for twenty-four hours there was still a decomposition, which continued, bat the action was extremely feeble. Two cells were allowed to remain arranged in closed circuit for fifteen days, a third being placed by the side, but with the terminals unconnected; at the expiration of this time the rise of liquid in the tubes was as follows:-

Rise of liquid in cells of closed Rise of liquid in cells of decircuit, in tubes of

Oxygen .0 .05 cubic inch. Oxygen .0 .02 cubic inch. $\begin{array}{llllll}\text { Olefiant gas } & 0.4 & \ldots & \text { Olefiant gas } & 0.3 & \ldots\end{array}$

Rise of liquid apparently due to voltaic action,

In oxygen tubes. . 0.03 cubic inch.

In olefiant gas tubes $\quad \cdot 0 \cdot 1 \quad$...

These quantities are too small to enable any satisfactory inference to be deduced as to the equivalents of these gases which contributed to electrolysis; the more so as the rise of liquid was not quite uniform, and the action due to solution was so much greater than that due to electrolysis.

I do not feel entitled to draw any other conclusion from this experiment than that there was a very feeble voltaic cur- 
rent produced by these gases; both the remaining oxygen and the olefiant gas were unaltered in character.

Experiment 11.-Oxygen and carbonic oxide produced notable effects upon the iodide, and slight symptoms of decomposing water; a few bubbles gathered upon the electrodes of an interposed voltameter; the effects continued; and at the expiration of fifteen days, the following was the state of the tubes in two cells, put aside as in the last experiment:Rise of liquid in cells of closed Rise of liquid in tubes of decircuit, tached pair, cubic inch. cubic inch. In oxygen tubes. $\cdot 0 \cdot 12$ In oxygen tubes.. $.0 \cdot 02$ In carbonic oxide tubes 0.93 In carbonic oxide tubes 0.7 Rise of liquid apparently due to voltaic action, In oxygen tubes.$\cdot 0 \cdot 1$ cubic inch. In carbonic oxide tubes 0.23

Before the hattery was charged for this experiment, the carbonic oxide had been carefully freed from carbonic acid by caustic potash. After action, the liquid gave a slight precipitate with lime-water, showing that carbonic acid had been produced by the action. In this experiment the rise was more uniform in the different tubes than in the last, and the action more decided. The results, although on a small scale, appear more definite; thus we get the proportion as $1: 2 \cdot 3$; and as the combining volumes of oxygen and carbonic oxide are as one to two, if we add the local action due to the oxygen of the air in solution, 1 to 2.3 is as near an approximation as can be expected. Though much superior to olefiant gas, the action of carbonic oxide is, however, very feeble when compared with that of hydrogen.

Experiment 19.-Oxygen and chlorine. Very considerable action on the iodide at first, but not constant; it abated within the first hour, and after twenty-four hours the action was extremely feeble, scarcely perceptible; the water had risen nearly to the top of the chlorine tubes, but the level in the oxygen tubes was unaltered. The chlorine was negative to oxygen, or in other words, the oxygen was in its voltaic bearing to chlorine as hydrogen to oxygen.

As in this experiment the water level in the oxygen tubes was unaltered, it appeared that this gas had little to do with the action, I therefore,

Experiment 14,-Charged the alternate tubes of a battery with chlorine and dilute sulphuric acid; the amount of action was much the same as in experiment 13, and equally transitory; a few gaseous bubbles were perceptible on the platinums in the oxygen cells, but not in sufficient quantity for 
examination. It is well known that chlorine of itself will slightly decompose water, forming hydrochloric acid, and evolving oxygen, and there is little doubt that the voltaic action here observed was due to this. There was no appearance of the platinum having been attacked in several experiments which I made with chlorine. So slight a chemical action will, however, give rise to voltaic effects, that the absence of any apparent corrosion is not conclusive. It is stated by chemists that gaseous chlorine will not attack platinum, but that it is only when nascent it combines with this metal; non constat however, that in the gas battery the chlorine at the initiatory instant of its electro-synthesis may not be in a state analogous, as to its chemical energies, to that converse state called nascent, and therefore we cannot venture to negative the possibility of the platinum being slightly attacked. This circumstance, added to its extreme solubility and power of decomposing water, makes chlorine rather an unsatisfactory element for the class of actions developed by the gas battery.

Solutions of bromine, chlorine and iodine, have been before experimented on ( $I$ believe by Dr. Schœnbein and M. Becquerel) as to their voltaic relations, but in examining the voltaic relations of bodies in a gaseous state, or to express myself with more caution, in a state passing from gaseous to liquid, I tried,

Experiment 15,-One set of tubes charged with gaseous chlorine, and the alternate tubes with solutions of bromine and iodine. The chlorine was negative to both, i.e. was to these as oxygen to hydrogen.

I now tried hydrogen with several gases, but as it was next to impossible (I found it quite impossible), in experiments on a large scale, perfectly to exclude atmospheric air from the solution*, voltaic action was produced in every case; and as with one exception (chlorine) oxygen was the most powerful electro-negative gas, the action of the atmospheric air entively masked any effect which might have been produced by the other gases + . I shall, therefore, not go through these experiments in detail, but mention one or two only which appear interesting, for the reasons which I shall state.

Experiment 16.-Chlorine and hydrogen gave very power-

* Gases will creep by a species of endosmose through water. Some time ago I kept inverted over water for two months, a vessel divided by a diaphragm of porous ware, on one side of which was oxygen gas, on the other hydrogen; the diaphragm was constantly wet from capillary attraction; at the end of that period the water had risen considerably, and the gases on each side detonated.

$\uparrow$ See Postscript. 
ful effects, as was expected by Dr. Schœnbein*; water was decomposed between platinum electrodes by two cells. This is the most powerful gas battery $\dagger$, but not very satisfactory, for the reasons above stated, experiment 13.

Experiment 17.- Hydrogen and carbonic oxide were tried in order to ascertain their voltaic relations. Hydrogen was much more electro-positive than carbonic oxide, or rather formed, with the oxygen of the atmospheric air in solution, a combination which overpowered the opposite tendency of the carbonic oxide and air.

Experiment 18.-Chlorine and olefiant gas gave a very feeble effect upon iodide of potassium. After four hours the liquid in the olefiant gas tubes had not risen more in the closed circuit than in the detached pair; the chlorine was nearly all absorbed in solution.

Experiment 19.-Chlorine and carbonic oxide gave very notable effects; ten cells decomposed water. From the extreme solubility of the former gas, the equivalent relationship could not be ascertained.

It now occurred to me that as oxygen and hydrogen are evolved from water by electrolysis, and conversely form water by electro-synthesis, so some other gases which are evolved from certain electrolytes by voltaic action, might, when arranged as a gas battery with the electrolyte from which they are evolved, give rise to a current, although they would not do so when arranged in circuit with a different electrolyte. To test this view I tried,

Experiment 20,-Oxygen and deutoxide of nitrogen in alternate tubes of the gas battery, with dilute nitric acid; the effects were however precisely similar to experiment 8 , viz. a very feeble action for a few minutes, then a cessation, and no continuous chemical action.

Experiment 21.-For the same reason oxygen and nitrogen, with solution of sulphate of ammonia, were tried ; this arrangement produced at first a slight effect upon the iodide, which soon ceased, and after several days there was no more rise of liquid in any cell of the closed circuit than in the detached

- See his letter, Phil. Mag., March 1843.

+ Chlorine, in its voltaic relations, may be considered as the converse of zinc, both decomposing water, but the one liberating oxygen, the other hydrogen; thus a tube of the gas battery charged with chlorine, and having acidulated water as an electrolyte, and zinc as a positive element, forms a combination of which one pair will decompose water. I have tried to render this combination practically useful, by charging the negative cell of a nitric acid battery with peroxide of manganese and muriatic acid, but the supply of chlorine thus obtained is insufficient for quantitative voltaic effects, though the intensity is great. 
cell; the rise of liquid in both was very trifling indeed (about 0.01 cubic inch), and had evidently nothing to do with voltaic action. In this experiment, and in every experiment that $I$ have tried, I have perceived a trifling action for the first few minutes. This I should have attributed to accidental causes, such as slight impurities in the gases, slight metallic deposits on the plates, \&c., but that it is always in the direction which theory would indicate. Thus in the present experiment, the appearance of iodine indicated oxygen to have the same voltaic relation to nitrogen as it has to hydrogen. This temporary effect, therefore, appears to me analogous to that action called by continental experimentalists polarization, an apparent tendency to action, i.e. an arrangement of molecules preliminary to electrolysis, but incapable of producing a continued current. In this and many other experiments with the gas battery I have observed this effect, but have never been able to produce any chemical change or electro-synthetic absorption of nitrogen.

Experiment 22.-As oxalic acid when electrolysed evolves at the anode a mixture of oxygen and carbonic acid, and at the cathode hydrogen and carbonic oxide; for the reasons above stated, I charged a gas battery with carbonic acid and carbonic oxide in the alternate tubes, and with oxalic acid as an electrolyte; a slight effect was produced, the carbonic oxide being to the carbonic acid as hydrogen to oxygen; but the current was evidently due to the atmospheric air in solution combining with the carbonic oxide; this I proved by some of the test experiments before mentioned, which I need not recapitulate.

Experiment 23.-Hydrogen, nitrogen, and sulphate of ammonia. This combination also gave effects with which the nitrogen appeared to have nothing to do, this gas being perfectly unaffected; I tried other experiments on this point, but they all led to the same conclusion, viz. that my idea of realizing a voltaic action by conversion of the ordinary effects of electrolysis was erroneous. It may be that the above gaseous products of electrolysis are secondary, and that water is the only electrolyte in these cases; but for this, as for many other theoretical questions, there are so many arguments pro and con, that it is not worth while to dilate on them unless they can be shown to lead, or to be likely to lead, to some new valuable facts or natural relations.

Reviewing the above experiments, it appears that clilorine and oxygen, on the one hand, and hydrogen and carbonic oxide, on the other, are the only gases which were decidedly capable of electro-synthetically combining so as to produce a Phil. Mag. S. 3. Vol. 24. No. 160. May 1844. 2 A 
354 Mr. Reuben Phillips on the Elasticity of Gases.

voltaic current*. I should perhaps except olefiant gas, which appears to give rise to a continuous though extremely feeble current; and the vapours of bromine and iodine, were they less soluble, would probably also be found efficient as electronegative gases.

[To be continued.]

LI. Some Remarks on the Elasticity of Gases. By Rauben Puillips.

SrR,

To Richard Taylor, Esq.

THE pressure exercised by a gaseous volume on surrounding matter, as measured by its pressure on a small square unit, has been found to vary as the volume, or that the volume, plus the pressure on the square unit, is always equal, the ponderal quantity of gaseous matter being of course constant. Now, if a gaseous volume may be represented by the symbol $(v y)^{3}$, in which $y$ is the distance between the atomic centres, and $v$ the number of times $y$ is contained in one side of the cube $(v y)^{3}$, then $\frac{(v y)^{3}}{y^{3}}=\frac{(v \cdot \overline{y+z})^{3}}{(y+z)^{3}}, z$ being any positive or negative quantity, but so taken as not to render the fraction 0 , or $\propto$; therefore the gaseous volume varies as the cube of $y$; but the pressure also varies as the volume, and therefore as $y^{3}$. If the pressure be assumed to proceed from the mutual repulsion of the gaseous particles, it is hereby shown that such repulsion varies as the cube of the distance between the atomic centres. This seems to be an exception to the general law, whereby forces emanating from a centre vary as the square of their distance from that centre, which appears to point out as a fact, that gaseous repulsion does not solely proceed from centres.

I remain, Sir,

Your most obedient Servant,

Monmouth Street, Topsham. ReUben PHILlips.

L1I. On some nero Species of Biliary and Intestinal Concretions. By Thomas Taylor, Esq.

Dear Sir, To Richard Taylor, Esq.

GEVERAL statements having appeared in the continental $\$$ journals with regard to the composition of some neto species of biliary and intestinal concretions, I have received permission from the Museum Committee of the Royal College of Surgeons to state, that in the second and third parts of the

- See Postscript. 